\title{
ENSINO DE HISTÓRIA E CIDADANIA: UMA PROPOSTA DE ANÁLISE DAS INSTITUIÇÕES ESCOLARES NA PERSPECTIVA DO INTERACIONISMO SIMBÓLICO ${ }^{1}$
}

\author{
THE TEACHING OF HISTORY AND CITIZENSHIP: AN ANALYSIS FROM THE POINT \\ OF VIEW OF SYMBOLIC INTERACTIONISM OF SCHOOL INSTITUTIONS
}

Rivail Carvalho Rolim ${ }^{2}$

\begin{abstract}
RESUMO: Durante a década de 1990 houve uma forte mobilização para mudar o sistema educacional do país, objetivando formar cidadãos detentores de uma postura ética, compromisso social e político, para construir uma sociedade mais justa e solidária. Para isso, foram formuladas propostas educacionais, como a Lei de Diretrizes e Bases da Educação e os Parâmetros Curriculares Nacionais, pois o entendimento era de que a educação tinha um papel crucial no desenvolvimento das pessoas e das sociedades. Diante do exposto, temos como objetivo apresentar uma proposta de análise do tema da cidadania, no ensino de História, nas instituições escolares, na perspectiva do interacionismo simbólico. Com isso, pretendemos contribuir para a compreensão da implantação de políticas públicas no país; fornecer elementos que auxiliem no entendimento das instituições escolares, e da ação do professor no chão da escola, quando uma nova proposta pedagógica é apresentada.
\end{abstract}

Palavras-chave: Cidadania. Instituições escolares. Ensino de História.

ABSTRACT: The 1990s saw a strong trend towards changes in Brazil's educational system aiming at the formation of citizens imbued with an ethical stance and socialpolitical commitment for the construction of a more just and participatory society. Educational proposals, such as the Guideline and Bases of Education and the National Curriculum Parameters, have been prepared since an agreement was reached that education had a relevant role in the development of people and society. Current paper presents an analysis on citizenship in the teaching of History in schools from the point of view of symbolic interactionism. It is a contribution towards the understanding of the establishment of public policies in Brazil and the provision of items that help in the understanding of school institutions and teachers' activities in the school when new pedagogical proposals are suggested.

Keywords: Citizenship. School institutions. Teaching of History.

\footnotetext{
1 Agradeço as críticas e sugestões feitas pela Prof. Marlene Rosa Cainelli, professora de Metodologia e Prática de Ensino de História, na Universidade Estadual de Londrina.

2 Professor Adjunto da Universidade Estadual de Maringá. Doutor em História pela Universidade Federal Fluminense.
} 


\section{Introdução}

A redemocratização, ao longo da década de 1980, acarretou uma mobilização significativa, de norte a sul do país, com o intuito de mudar o sistema educacional, objetivando formar cidadãos detentores de uma postura ética, compromisso social e político, para construir uma sociedade mais justa e solidária. Nesse sentido, no final da década seguinte, foram aprovadas a Lei de Diretrizes e Bases da Educação Nacional, em 1996, e os Parâmetros Curriculares Nacionais, em 1998. No bojo dessas mudanças, surgiram também as Diretrizes Curriculares do Ensino Fundamental, em 1998, assim como as Diretrizes Curriculares para os Cursos Superiores de História, em 2001, e a aprovação da Lei que torna obrigatória a temática da História e Cultura Afro-Brasileira, em 2003, sendo incluída a Cultura Indígena no ano de 2008.

A busca de uma reformulação do ensino pretendia uma sintonia com a Constituição de 1988, denominada Constituição Cidadã, a qual anunciava que um dos objetivos fundamentais da República Federativa do Brasil era construir uma sociedade livre, justa, solidária, promover o bem de todos, sem preconceitos de origem, raça, sexo, cor, idade e quaisquer outras formas de discriminação, do mesmo modo que garantir o desenvolvimento nacional, a erradicação da pobreza e da marginalização, além de reduzir as desigualdades sociais e regionais (BRASIL, 1988).

Nesses períodos em que novas propostas curriculares e experimentos pedagógicos são apresentados, é essencial delinearmos o alcance das formulações na realidade escolar, pois a "sustentabilidade no mundo do currículo escolar está intimamente relacionada com a recepção que o currículo tem nos públicos externos", por conseguinte, torna-se condição sine qua non observar as "circunstâncias históricas das forças de mudança antes de considerarmos o seu potencial progressista ou regressivo" (GOODSON, 2013, p. 14, 21). Salientamos que os Parâmetros Curriculares Nacionais (PCN) orientaram a formulação de currículos, a produção de livros didáticos e a avaliação do sistema de educação nas duas últimas décadas no país, sendo substituídos pela Base Nacional Curricular Comum, em 2017. 
O entendimento era de que as mudanças curriculares eram importantes, pois a educação tem um papel crucial no desenvolvimento das pessoas e das sociedades, e portanto, teria de ser construída uma "escola voltada para a formação de cidadãos" (BRASIL, 1998a, p. 5). Quanto a essa função das instituições escolares, Philipe Perrenoud (2005, p. 155) ressalta que elas têm desempenhado um papel fundamental na criação de países democráticos, embora o autor faça a ressalva de que um nível elevado de escolarização não significa, necessariamente, a garantia da liberdade, igualdade e fraternidade, nem os valores democráticos.

Ante o exposto, objetivamos, neste artigo, apresentar uma proposta de análise do tema da cidadania, no ensino de História, nas instituições escolares, considerando seu aparecimento, com bastante evidência, nos textos educacionais como a Lei de Diretrizes e Bases da Educação (1996) e os Parâmetros Curriculares Nacionais (1998) que têm orientado as políticas educacionais nas duas últimas décadas. Como exemplo, citamos o fato de que, para o governo federal, era necessário "unir esforços entre as diferentes instâncias governamentais e da sociedade, para apoiar a escola na complexa tarefa educativa", visando o "pleno desenvolvimento do educando, seu preparo para o exercício da cidadania" (BRASIL, 1998a, p. 10, 19). Entendemos que, com este trabalho, podemos contribuir para o entendimento da implantação de políticas públicas no país, e fornecer elementos auxiliadores na compreensão das instituições escolares, e na ação do professor no chão da escola, quando uma nova proposta pedagógica é apresentada.

Empreendemos nossas reflexões na perspectiva do interacionismo simbólico, baseado no postulado teórico e metodológico de que o indivíduo deve ser compreendido dentro do particular contexto social no qual foi formado; nesse caso, que age em relação ao mundo, observando todo o possível, como ideais norteadores e situações nas quais se depara em seu dia-a-dia, fundamentandose nos significados que estes thes oferecem. Os significados de tais elementos são provenientes da (ou provocados pela) interação social que se mantém com as demais pessoas. Tais significados são manipulados por um processo interpretativo (e por esse modificado) utilizado pela pessoa ao se relacionar com 
os elementos com os quais entra em contato (MEAD, 2010; BLUMER, 1980; BERGER; LUCKMANN, 1974).

\section{Políticas públicas na educação $e$ as instituições escolares: abrangências e possibilidades}

Ao longo da década de 1990, o governo federal procurou materializar nos textos educacionais o que havia sido anunciado na Constituição de 1988 e na Lei de Diretrizes e Bases da Educação de 1996, formulando os Parâmetros Curriculares Nacionais (1998), pois entendia que estávamos diante de uma nova realidade que impunha uma "revisão dos currículos, que orientam o trabalho cotidianamente realizado pelos professores e especialistas em educação do nosso país" (BRASIL, 1998a, p. 5)33. A diretriz desse documento consistia que as pessoas adotassem "dia a dia atitudes de solidariedade, cooperação e repúdio às injustiças, respeitando o outro e exigindo para si o mesmo respeito" (BRASIL, 1998c, p. 7).

No tocante ao ensino de História, de acordo com os PCN, este poderia contribuir para a formação do "estudante como cidadão, para que assumisse formas de participação social, política e atitudes críticas diante da realidade atual, aprendendo a discernir os limites e as possibilidades de sua atuação, na permanência ou na transformação da realidade histórica na qual se insere" (BRASIL, 1998b, p. 36). A aprovação de uma lei tornando obrigatório o ensino de História e Cultura Afro-Brasileira e Indígena, na primeira década deste século, também seguiu o princípio educacional de construir uma sociedade que procurava integrar, e incluir, sujeitos excluídos. Como assinala Selva Guimarães e Marco Silva (2012, p. 45), reconhecer o "pluralismo no interior da sociedade brasileira e a educação escolar como um espaço de afirmação de identidades diversas".

\footnotetext{
3 Os Parâmetros Curriculares Nacionais são diretrizes elaboradas pelo governo federal em 1997 com o intuito de subsidiar e orientar a elaboração ou revisão curricular, a formação inicial e continuada de professores; as discussões pedagógicas internas às escolas; a produção de livros e outros materiais didáticos e a avaliação do sistema de educação.
} 
Ainda, conforme Marcos Silva e Selva Guimarães, isso havia emergido como reação às demandas, lutas e necessidades de determinados setores sociais, especialmente daqueles considerados "minorias", pois suas histórias deveriam ser valorizadas e reconhecidas (GUIMARÃES; SILVA, 2012, p. 47). Com todas essas mudanças ocorrendo, Circe Bittencourt destacava que "a utilização do termo cidadania encontrava-se disseminada em uma profusão de textos e discursos acadêmicos, políticos, especialmente naqueles destinados às questões educacionais". Complementa a autora que da História se esperava "uma contribuição relevante na formação de um determinado tipo de cidadão (BITTENCOURT, 1997, p. 20-21).

Estávamos, portanto, em um ambiente no qual a "cidadania, literalmente, caiu na boca do povo", para usarmos palavras de José Murilo de Carvalho (2005). Com a percepção de que a construção de uma nova sociedade estava ao alcance de nossas mãos, que havia chegado o momento, alguns pesquisadores começaram a ressaltar que deveríamos ir além do que estava formulado nos textos educacionais do governo federal. Circe Bittencourt (1997, p. 20-21), embora fosse uma das consultoras dos PCN, por exemplo, destacou que "o conceito de cidadão que aparece nos conteúdos era limitado à cidadania política, à formação do eleitor dentro das concepções democráticas do modelo liberal".

Katia Abud sublinhava que nesse momento de reformulação curricular, pelo qual passava o país, era necessário romper com o viés centralizador da proposta. Em sua perspectiva, não se podia alijar os professores do processo, logo, era imprescindível não vê-los como "incapacitados de construir sua história e de fazer, em cada momento de sua vida escolar, seu próprio saber" (ABUD, 1997, p. 40). Para esta pesquisadora da área de ensino, era oportuno seguir um caminho parecido com aquele em que ocorreu a separação de ensino de História e Geografia, nos anos 1980, o qual havia sido buscado pelos professores dessas duas áreas de conhecimento no interior das condições regionais, em suas próprias escolas, e com seus próprios meios.

Pesquisas sobre o papel que escolas e professores poderiam desempenhar para efetivar o que estava contido nos textos educacionais foram realizadas. As conclusões foram no sentido de mostrar a sala de aula como um espaço privilegiado, à medida que o professor iria "ensinar o aluno a captar e a valorizar 
a diversidade dos pontos de vista", dar-lhe "as condições de participar do processo do fazer, do construir a História" (SCHMIDT, 1997, p. 57). Acresce a pesquisadora que em sala de aula se realizava um espetáculo cheio de vida e de sobressaltos, pois os alunos "desejam pensar por si mesmos, ser reconhecidos, ser libertados em sua originalidade na compreensão e no resgate de sua história" (SCHMIDT, 1997, p. 56). Selva Guimarães e Marcos Silva (2012, p. 48) salientam a importância de que nos diferentes espaços educativos os professores poderiam "desconstruir discursos antidemocráticos, monoculturais, difusores de estereótipos e preconceitos de classe, raça, religião".

Assim sendo, havia grandes esperanças de construirmos uma sociedade na qual os professores fossem, dia após dia, cumprindo os objetivos do Ensino Fundamental, conforme preceituam os PCN, qual seja fazer os alunos se tornarem capazes de compreender que a cidadania implicava ter atitudes de solidariedade, cooperação e repúdio às injustiças, assim como entender ser necessário respeitar o outro e exigir, para si, o mesmo respeito (BRASIL, 1998a, p. 55). Quanto à história do Brasil, "levará em conta as contribuições das diferentes culturas e etnias para a formação do povo brasileiro, especialmente das matrizes indígena, africana e europeia" (BRASIL, 1998a, p. 57).

No entanto, pesquisas relativas à prática dos professores começaram a apontar que os currículos prescritos poderiam ter uma força, um poder diretriz, mas era necessário atentar para o fato de que as disciplinas não eram meros espaços de vulgarização de saberes, nem tampouco de adaptação ou simplesmente transposição de ciências de referência (GUIMARÃES; SILVA, 2012, p. 30). Sobre essa questão, Philipe Perrenoud (2005, p. 13) lança a seguinte indagação: De que serve ensinar o respeito, a tolerância, a cooperação se o sistema educacional pratica a segregação, a humilhação ou a competição?

Selva Guimarães e Marcos Silva (2012, p. 61) enunciam a necessidade de entender que os professores tinham "alguma autonomia ante as demandas do Estado, logo, poderiam questionar, criticar, subverter os saberes e as práticas no cotidiano escolar". Alertavam, também, ser fundamental levar em consideração que entre os currículos prescritos, e os vividos, nas aulas de História, havia diversas mediações entre os sujeitos envolvidos no processo de ensinoaprendizagem, assim como saberes diferentes, como imprensa, fontes de época, 
textos, filmes, literatura, e práticas institucionais burocráticas e comunitárias, em contextos muito diferenciados (GUIMARÃES; SILVA, 2012, p. 30). Quanto a esses saberes diferentes, vale lembrar as palavras de Philipe Perrenoud (2005, p. 10) de que "é inútil exigir da escola que professe valores de solidariedade que a sociedade ignora ou escarnece no dia-a-dia em suas mídias, em sua vida política, naquilo que se passa nos estádios, nas empresas, nos bairros".

Não é sem sentido que as abordagens sobre o processo de ensinoaprendizagem começaram a fazer referência ao currículo formal, ao currículo real e ao currículo oculto, justamente para enfatizar que, embora houvesse um projeto educativo sistematizado com finalidade de produzir aprendizagem, no espaço da escola se vivenciavam todos os tipos de influências que afetavam, sobremaneira, a aprendizagem dos alunos e o trabalho dos professores, pois diziam respeito às relações estabelecidas com o meio social. Com o avanço das pesquisas sobre o sistema educacional foi ficando claro que a sustentabilidade das propostas curriculares estava relacionada à recepção dos conteúdos pelas secretarias de educação, pelos núcleos de ensino, pela equipe pedagógica na escola e pelo professor em sala de aula.

$\mathrm{Na}$ esteira das reflexões de Roger Chartier (1992, p. 214), podemos assinalar que "ler é uma prática criativa que inventa significados e conteúdos singulares, não redutíveis às intenções dos autores dos textos ou dos produtos dos livros", logo, precisamos entender que "cada leitura realizada por cada leitor é, na verdade, uma criação secreta e singular". E conclui o historiador francês: "qualquer compreensão de um texto, não importa o tipo, depende das formas com as quais ele chega até seu leitor" (CHARTIER, 1992, p. 220). Diante dessas assertivas, podemos afirmar que os PCN foram sujeitos a essas leituras criativas, porque as equipes educacionais nas secretarias estaduais, a equipe pedagógica na escola, e o professor em sala de aula, fizeram uma criação secreta e singular do texto educacional.

Portanto, em se tratando do ambiente escolar, equipe pedagógica e professores passaram a realizar as leituras do texto educativo que tinha como finalidade produzir a aprendizagem com os ideais da democracia e da cidadania. No entanto, é preciso buscarmos um meio de compreender os paradigmas de leituras predominantes, nesse grupo de leitores, em cada um dos lugares 
espalhados pelo país, pois a caracterização desses modos de leitura se torna "indispensável a qualquer abordagem que pretenda reconstruir a maneira como os textos puderam ser apreendidos, compreendidos e manipulados" (CHARTIER, 1992, p. 226-227).

Para determinarmos os paradigmas de leituras desse grupo de leitores espalhado pelo país, necessariamente avançaremos na compreensão das instituições escolares, tendo em vista ser nesse espaço que ocorre o processo de ensino-aprendizagem. Para isso, é condição sine qua non aprofundarmos a análise sobre os processos organizativos, pois implica na compreensão de como são estruturados os coletivos humanos em prol de um projeto, de um objetivo. Como pondera Mary Douglas (2004, p. 35) "o compromisso que subordina os interesses individuais a um todo social mais amplo deve ser explicado".

Com isso, algumas indagações devem vir à tona. Os agentes educativos foram envolvidos em um sistema de confiança no interior da instituição escolar, onde vislumbraram que estavam construindo um bem coletivo? Colaboraram, desinteressadamente, uns com os outros, para construírem esse bem coletivo? Professores entenderam que sua contribuição, nesse universo imenso de instituições, faria a diferença? Ou, pelo contrário, sendo o responsável direto pelo processo de ensino-aprendizagem o professor não observou se não poderia se sair melhor agindo por conta própria, ignorando os textos educacionais?

Alguns autores que, primeiramente, buscaram entender como são estruturados os coletivos humanos em prol de um projeto, de um objetivo, chegaram à conclusão de que as instituições possuem um desenho formal para responder a determinadas necessidades, ou cumprir objetivos previamente traçados, logo, estão configuradas, racionalmente, para que tais intentos sejam concretizados plenamente. Max Weber (1999, p. 198/233), por exemplo, ressaltava que, no estado moderno, a burocracia se caracteriza pela racionalidade, previsibilidade, e disciplina dos funcionários, pois obedece aos objetivos a que foram determinados.

Com essa perspectiva de entendimento do funcionamento das instituições na modernidade, as pesquisas foram no sentido de mostrar que para se atingir plenamente os objetivos, era necessário controlar os resultados obtidos, como realizar constantes avaliações dos indivíduos que as integram, pois estes 
constituíam uma totalidade articulada orientada para realizar seus intentos, independentemente da dinâmica social ou das relações estabelecidas com a sociedade. No caso das instituições escolares, o pressuposto era de que atuariam para orientar as ações de diferentes agentes educativos, transformando ações individuais em ações coletivas para cumprir o que está estabelecido nos textos educacionais.

Entretanto, os problemas mais evidentes nessas pesquisas foram tentar mostrar que as instituições possuem uma lógica própria, formam um sistema fechado e autônomo, e para compreendê-las é dispensável o estudo de seus participantes. O pressuposto, portanto, é de que os agentes desempenham suas funções como se estivessem cumprindo obrigações comuns no interesse de todos. Todavia, ficou evidente que as instituições estão bem longe de agir de forma homogênea, orientadas para um interesse comum, porque refletem as divisões existentes na sociedade e têm uma dinâmica a partir dos constrangimentos e pressões sociais (DREYFUS, 2012).

Devemos, portanto, levar em consideração que há um contraste entre o desenho formal e as produções reais das instituições escolares; há uma evidente disparidade entre esses dois âmbitos. Por isso, as contradições entre esses domínios devem ser explicadas, pois são ações reais no interior de cada uma das instituições de ensino espalhadas por este país. Muitas vezes, atividades antagônicas se desenvolvem de maneira concomitante e podem afetar a atividade central, e formal, definida pela organização. Em suma, as instituições escolares, como outras, são espaços sociais nos quais os indivíduos agem. Conforme escreve Herbert Blumer (1980, p. 136), "uma rede ou uma instituição não funciona automaticamente devido a alguma dinâmica interna ou a exigências do sistema, mas sim porque os indivíduos, em diferentes pontos da urdidura, realizam atos, e estes constituem resultado da maneira pela qual definem a situação em que são chamados a agir".

\section{Cidadania e direitos nas instituições escolares: a perspectiva interacionista}


Depois desses apontamentos relativos às instituições escolares, cabe avançarmos na compreensão das ações sociais levadas a cabo, pelos agentes educativos, em seu interior. Ressaltamos que uma ação coletiva depende do "encadeamento complexo de trocas múltiplas recíprocas, diretas e indiretas"; essencial, portanto, entendermos como acontecem as relações de reciprocidade e a afinidade entre todos os envolvidos no processo de ensino-aprendizagem (DOUGLAS, 2004, p. 46, 49). Mesmo porque os indivíduos que integram essas instituições podem realizar ações em prol de objetivos coletivos ou para fins particulares, seja de um grupo ou para ele próprio.

No ambiente escolar haverá a formação de diferentes grupos que interpretarão as regras erigidas pela instituição na qual estão vinculados, seja a partir de interesses coletivos, seja para fins particulares de uma categoria ou para si próprios. Como escreve Herbert Blumer (1980, p. 123), "os indivíduos podem agir isolada ou coletivamente, além de poderem tomar atitudes em nome de alguma organização ou grupo de outras pessoas". Por conseguinte, é grande a possibilidade de nos depararmos com diversos grupos de agentes educativos em função das distintas realidades histórico-sociais de cada instituição educativa no país.

As instituições podem até ter um desenho formal, mas é no âmbito concreto de suas ações que as práticas são, de fato, produzidas. É no chão da escola que ocorrem as interações sociais entre os agentes educativos, logo, os textos educacionais podem estar sujeitos a modificações e reformulações. Como enuncia Blumer (1980, p.122), "o agente seleciona, modera, susta, reagrupa e transforma os significados sob o ponto de vista da situação em que se encontra e da direção dos seus atos".

Realçar que os textos educacionais estão sujeitos a modificações, e reformulações, diz respeito ao fato de que agentes educativos agem a partir de uma realidade social, nesse caso, eles se comportam de acordo com as interações sociais estabelecidas com a sociedade. Devemos entender que essas pessoas trabalhadoras do interior das instituições escolares fazem parte de um mundo mais amplo; sua ação está perpassada por seu pertencimento à sociedade. Como destaca Georg Mead (2010), na experiência de vida as pessoas internalizam pautas socioculturais ao estabelecer interações sociais com 
membros do grupo que participam do seu processo de formação, de seu desenvolvimento. Portanto, a consciência do indivíduo se constitui no processo social, pelas interações sociais estabelecidas com outros que estão envolvidos em uma experiência compartilhada (MEAD, 2010, p. 165-166). Como pontuam Berger e Luckmann (1974, p. 73), "o eu só pode ser compreendido dentro do particular contexto social em que foi formado".

Diante disso, temos de avançar no entendimento de como os significados são manuseados no processo interpretativo. Com as reflexões de Blumer (1980, p. 120), observamos que "ignorar o significado dos elementos com que os seres humanos se relacionam é falsificar o comportamento que se analisa". A origem do significado não é algo intrínseco ao elemento, como se fosse simplesmente buscar a definição contida através da observação. Para exemplificar, as noções de sociedade livre, justa e solidária presentes nos textos educacionais, podem até possuir uma definição nos clássicos do pensamento político, contudo os significados erigidos no interior das escolas envolvem um processo interpretativo. Podem, inclusive, assumir significados diferentes para os agentes educativos a partir da experiência de cada um, vivenciada em determinada realidade histórico-social. Em outras palavras, não basta identificar o significado contido nos documentos oficiais para entendermos como foi apreendido, compreendido e manuseado pelos agentes educacionais.

A procura da explicação, portanto, deve partir do pressuposto de que o significado é produzido em um processo de interação humana, pois é um produto social, são criações elaboradas em e através das atividades humanas. Como se trata de um processo de interação social, a "interpretação não deve ser considerada como uma mera aplicação de significados existentes, mas sim como um processo formativo em que os significados são utilizados e trabalhados para orientar e formar as ações" (BLUMER, 1980, p. 122).

Quando os agentes se depararam com diretrizes educacionais que deveriam trabalhar no sentido de promover o bem de todos, sem preconceitos de origem, raça, sexo, cor, idade e quaisquer outras formas de discriminação, não fizeram uma aplicação automática no processo de ensino-aprendizagem, como se fosse uma simples questão de transposição de conteúdo, e se essas noções tivessem um status fixo que devessem ser ensinadas. É necessário entender que 
o texto pode possuir diferentes significados para diferentes pessoas, pois é gerado a partir da maneira pela qual ocorre a interação social (BLUMER, 1980, p. 127-128).

Tratamos sobre como os significados são manuseados no processo interpretativo; contudo, para progredirmos na compreensão do funcionamento das instituições escolares, temos que compreender as atividades desempenhadas pelos indivíduos ao entrarem em contato com os outros e ao lidarem com as sucessivas situações que enfrentam. Conforme assinala Herbert Blumer (1980, p. 125), "os homens, ao interagirem uns com os outros, devem considerar o que cada um faz ou está para fazer; são obrigados a dirigir seu próprio comportamento ou manipular as situações em função de tais observações".

Podemos afirmar, assim, que face às ações governamentais - formulação das diretrizes curriculares - muitos agentes educacionais fizeram uma análise das propostas para adequá-las às suas atividades em estados, municípios e escolas. Nessas situações ocorreu um processo de interpretação desses documentos, pois diante de algo novo que estava sendo apresentado aos agentes, estes empreenderam uma avaliação, iniciaram, encerraram, abandonaram, adiaram ou mesmo confinaram ações a uma mera intenção. A esse respeito, Blumer (1980, p. 134) destaca que no estudo das coletividades é fundamental ter em mente que a ação conjunta constitui um encadeamento dos atos isolados dos participantes.

Essas coletividades que formaram um paradigma de leitura foram constituídas em determinada região, estado, escola. Vale lembrar ser o indivíduo que integra essa coletividade não um simples respondente, mas sim um agente "que necessita elaborar uma linha de ação de acordo com os elementos que verifica, ao invés de simplesmente emitir uma resposta à ação sobre sua organização" (BLUMER, 1980, p. 131). Devemos acrescentar, ainda, que a ação conjunta "encontra-se tanto sujeita a pressões quanto a reforços, tanto a insatisfações quanto à indiferença; pode ser tanto desafiada quanto aprovada, tanto tratada com desinteresse quanto revitalizada com o sopro de novos alentos" (BLUMER, 1980, p. 135).

Fizemos referências às ações, porém é necessário frisar que as experiências humanas não são simplesmente formas preestabelecidas de ação 
conjunta, como se o indivíduo estivesse sempre vivendo em uma ordem fixa e redutível a uma série de regras, normas, valores, e sanções, que determinam como proceder em diferentes situações. Com efeito, os indivíduos, ao se depararem com situações problemáticas nas quais as regras existentes ficaram inadequadas, arranjam outras linhas de ação a partir da nova realidade apresentada, mas sempre em uma interpretação e uma designação. Não obstante, é fundamental ressaltar que um novo tipo de ação jamais se origina separadamente de experiências passadas. Como atesta Blumer (1980, p. 136), "os participantes envolvidos na formação do novo comportamento conjunto trazem ao mesmo tempo o universo dos objetos, os conjuntos de significados e as sistematizações e interpretação que já possuem".

A formação de uma nova conduta surge sempre em um contexto de comportamentos coletivos anteriores, não surgem do nada, como se fosse uma criação espontânea. Para entendermos as ações dos agentes educativos não podemos desvinculá-las de seu encadeamento histórico. Baseados nos estudos sobre as coletividades, podemos afirmar que até se desenvolvem novas formas de ação diferentes daquelas anteriores, entretanto sempre haverá alguma ligação, ou continuidade, com a realidade social passada. É impossível, por conseguinte, compreendermos essa inovação que foi levada a cabo nas escolas espalhadas por todo o país, bem como as ações dos agentes educativos, desenvolvidas em seu interior, sem levarmos em consideração essa continuidade, essa permanência, pois de acordo com Blumer (1980, p. 137), o novo carrega marcas do passado.

Os agentes educativos, em todos os níveis organizacionais, estavam diante de algo novo - os Parâmetros Curriculares Nacionais - que apontava para a possibilidade de se constituir uma nova experiência educacional. No entanto, a transmissão de um novo sentido para as atividades educacionais pressupõe o reconhecimento social de que seja uma solução para os problemas existentes nos projetos pedagógicos, pois o entendimento era de que haviam sido deformados anteriormente, ao não primarem pelo ensino da democracia e da cidadania. Selva Guimarães (2016, p. 81) relata que, durante o regime militar, o professor ideal para o sistema educacional dos generais era aquele formado nos 
cursos generalizantes e superficiais, nos quais não se aprendia a refletir, a pensar de maneira crítica.

Nas novas propostas curriculares, o intento era de que os agentes educacionais desempenhassem um papel visando a uma formação aberta, cidadã e multicultural. O professor e os demais envolvidos no processo de ensinoaprendizagem deveriam ter autocompreensão de que esse era o novo sentido, socialmente atribuído, às ações realizadas nos espaços escolares. Qual o novo sentido? Que as ações promovessem o bem de todos, sem preconceitos de origem, raça, sexo, cor, idade e quaisquer outras formas de discriminação.

Nessa perspectiva, temos que discutir sobre até que ponto essa nova experiência educacional foi sedimentada, incorporada nas práticas existentes nas instituições escolares e tornou-se uma possibilidade objetiva para todos os agentes educacionais. Temos que observar em que medida os parâmetros curriculares nacionais geraram um novo tipo de ação pedagógica e formaram um novo hábito no interior das escolas, pois para que os conteúdos fossem transmitidos, os agentes educacionais deveriam corporificar o novo papel prescrito nos documentos governamentais. Entretanto, aprender um papel não é somente adquirir rotinas, implica possuir conhecimento dos valores e atitudes julgados adequados ao papel do professor que deveria eleger a cidadania como eixo da educação escolar. Analisar os papéis, ou ações, desses agentes educacionais, portanto, torna-se fundamental para conhecermos como os conteúdos foram trabalhados no chão da escola. Nessa direção, Berger e Luckmann (1974, p. 109) argumentam:

A análise dos papéis tem particular importância porque revela as mediações existentes entre os universos macroscópicos de significação, objetivados por uma sociedade, e os modos pelos quais estes universos são subjetivamente reais para os indivíduos.

Como estamos tratando do papel dos agentes educativos, temos de ter em mente a totalidade das ações realizadas nas inúmeras escolas espalhadas pelo país. Mensurar como as novas atividades foram institucionalizadas pelos agentes educacionais se torna essencial para entendermos de que forma os conteúdos dos parâmetros curriculares nacionais foram recepcionados e abordados. É crucial analisarmos como as secretarias de educação, com seu corpo de 
funcionários, as escolas, com sua equipe pedagógica, bem como os professores, empreenderam um trabalho no sentido de implementar as propostas curriculares de uma forma encadeada. Identificar a extensão dessa institucionalização, assim como o envolvimento dos diferentes agentes educativos, é condição sine qua non para entendermos se havia, ou não, espaço para ser sedimentado um novo hábito nas instituições educacionais.

Nesse sentido, o governo federal criou o programa Parâmetros em Ação, cujo propósito era "apoiar e incentivar o desenvolvimento profissional de professores e especialistas em educação, de forma articulada com a implementação dos Parâmetros Curriculares Nacionais, dos Referenciais Curriculares Nacionais para a Educação Infantil e para a Educação Indígena e da Proposta Curricular para a Educação de Jovens e Adultos" (BRASIL, 1999).

As pesquisas referentes ao sistema educacional do país, por exemplo, apontam que há uma ordem institucional muito fragmentada, com diferenças significativas entre as unidades escolares, mesmo no interior dos estados. Na trajetória histórica do país não houve uma integração das unidades, e estabelecimentos educativos, com o intuito de criar um sistema coerente, e adaptado, a uma entidade territorial, e administrativa, de âmbito nacional. O país oscilou entre centralização e descentralização do sistema de ensino, como em outras áreas, ao longo de sua trajetória histórica.

Nas reformas ocorridas, a partir da década de 1980, essa situação não se alterou porque a descentralização passou a ser a característica do sistema educacional, pois vários estados que levaram a cabo reformas escolares seguiram caminhos bastante distintos. Alguns procuraram romper, completamente, com os currículos anteriores; outros fizeram isto de uma forma mais gradativa, sem abandonar, completamente, determinados conteúdos (GUIMARÃES, 2016, p. 104). Não é sem sentido ter o diagnóstico realizado sobre o sistema educacional do país, ao longo da década de 1990, concluído que o mesmo se compõe de um quadro nacional confuso, fragmentado, com diferentes níveis de elaboração e de justificação (AZANHA, 2009).

Estamos diante de uma realidade social cuja característica é a segmentação educacional; como consequência, há a possibilidade de serem criados espaços de significação distintos, os quais se traduzem em conflitos entre 
grupos que têm diferentes formas de conceber o processo de ensinoaprendizagem, inclusive com o ensino de História, pois tem relação com a experiência vivenciada de cada agente educativo, em seu processo de formação e nas interações sociais estabelecidas, em cada realidade histórica. Como resultado, emerge uma multiplicidade de perspectivas sobre a sociedade total, cada qual o considerando do ângulo de uma dessas esferas de referência (BERGER; LUCKMANN, 1974, p.119).

Perante um sistema educacional que tem como característica a heterogeneidade surgem, portanto, os problemas de legitimação de um novo universo simbólico presente nas propostas de âmbito nacional, como os parâmetros curriculares. Salientamos que para compreendermos o alcance das orientações centrais contidas nos PCN, no desenho das propostas curriculares de cada um dos estados, e escolas, do país, necessariamente temos de entender toda a história de produção, pois os universos simbólicos são construídos por meio de objetivações sociais. Segundo Cláudia Galian (2014, p. 666), temos que identificar as tendências assumidas nas "propostas elaboradas pelos estados e municípios e daí até as salas de aula".

Algumas pesquisas realizadas sobre a efetivação dessa política pública empreendida pelo governo federal "que envolvam não apenas as escolas, mas pais, governo e sociedade", conforme destacam os PCN, têm mostrado as dificuldades para ser efetivada (BRASIL, 1998a, p. 09). Cláudia Galian (2014, p.654) alerta que "num país de grandes dimensões como o Brasil, onde se multiplicam manifestações culturais muito diversas, com um lamentável histórico de precariedade em relação aos aspectos socioeconômicos, notadamente no contexto educacional, essa tarefa é no mínimo arriscada".

Esta autora, ao destacar algumas dificuldades para se criar referências nacionais comuns nas propostas curriculares em todas as regiões do país, nos auxilia no entendimento da legitimação de novos universos simbólicos nas instituições escolares. De início, devemos lembrar que Peter Berger e Luckmann (1974, p. 147) advertiram, em seu trabalho, que a autonomia de espaços distintos de significação contribui para criar problemas especiais de legitimação, pois o "aparecimento de outro universo simbólico representa uma ameaça 
porque sua simples existência demonstra empiricamente que o nosso próprio não é inevitável".

Agentes educacionais nas secretarias de educação, nos núcleos educacionais e nas escolas, do mesmo modo que o professor, podem ter entendido que esse novo universo simbólico se constituiria em uma ameaça teórica "prática para a ordem institucional legitimada pelo universo simbólico em questão". Contudo, Berger e Luckmann (1974, p. 153) ressaltam, também, que todo universo simbólico é incipientemente problemático, logo, "a conduta do dissidente desafia a realidade social como tal, pondo em questão os procedimentos operatórios cognoscitivos e os normativos admitidos como certos".

O importante, para os objetivos das nossas reflexões, é frisarmos que os universos simbólicos são produtos históricos da atividade humana, socialmente construídos, logo modificam-se, e as transformações são realizadas pelas ações concretas dos seres humanos. Logicamente que esse processo não ocorre sem tensões, pois como salientam Berger e Luckmann (1974, p.148, 157), "o confronto de universos simbólicos distintos implica um problema de poder, a saber, qual das definições da realidade em conflito ficará fixada na sociedade." Nesse caso, temos que avançar nas pesquisas sobre os possíveis enfrentamentos e disputas dos universos simbólicos, haja vista que em relatório produzido no ano de 2010, o MEC identificou 60 propostas curriculares elaboradas pelas secretarias de educação, sendo 13 de secretarias municipais, 21 de secretarias estaduais e 26 propostas de ensino médio (GALIAN, 2014, p. 656).

Cláudia Galian (2014) fornece algumas informações sobre os conflitos entre o intuito do governo federal de construir referências nacionais comuns, bem como em definir um conteúdo mínimo a ser transmitido, e as propostas curriculares formuladas por estados e municípios com alguns temas considerados fundamentais na construção da cidadania que deveriam ser trabalhados nas escolas de forma transversal e interdisciplinar, tais como ética, meio ambiente, pluralidade cultural, saúde, orientação sexual, trabalho e consumo.

Para os objetivos do nosso trabalho, detemo-nos no tema da diversidade e da pluralidade cultural, um assunto essencial para o avanço da cidadania no país, porque no âmbito da escola poderiam ser desenvolvidos trabalhos sobre 
tolerância, respeito mútuo e solidariedade. Segundo os PCN, a escola deveria ser um local de aprendizagem de que as "regras do espaço público permitem a coexistência, em igualdade, dos diferentes, e que isso, alimentaria uma cultura de paz baseada na tolerância, no respeito aos direitos humanos e na noção de cidadania compartilhada por todos os brasileiros" (BRASIL, 1998c, p. 117). A disciplina de História, por exemplo, poderia dar sua contribuição ao abordar "os usos e costumes de diferentes grupos sociais em sua trajetória histórica", conforme propõe o documento (BRASIL, 1998b, p. 157). Contudo, em um relatório produzido pelo MEC, em 2010, chegou-se à conclusão de que havia pouco espaço nas propostas curriculares, de estados e municípios, nas diversas disciplinas, para a inclusão de temas referentes às culturas africana, afrobrasileira e indígena e relações étnico-raciais; pois ficaram restritas aos itens dos componentes em que havia obrigatoriedade (GALIAN, 2014).

Ao avançarmos na análise de alguns pesquisadores, vamos descortinando outros aspectos que precisamos observar para entendermos o funcionamento da instituição escolar, bem como do ensino de História no país. Gizelda Costa da Silva (2015, p. 197), ao fazer uma investigação sobre História e Cultura AfroBrasileira no ensino de História, na cidade de Uberlândia-MG, mostra que a luta por territórios curriculares é explícita e existe uma correlação de forças nos espaços de atuação a qual lei alguma é capaz de suprimir. Contudo, aponta um aspecto positivo: de que as práticas vão superando as dificuldades, apesar de ficarem sujeitas ao compromisso do professor, principalmente daqueles que participam de movimentos sociais, do movimento negro (SILVA, 2015).

Devemos salientar que a luta pelos territórios curriculares está presente também no ensino superior, à medida que o tema da Cultura Afro-Brasileira é pouco trabalhado nas disciplinas dos cursos de graduação no país. Hebe Mattos (2003, p. 131), por exemplo, alega que uma pesquisa histórica sobre a história social da escravidão repercute de forma limitada fora do círculo de especialistas; do mesmo modo, a História da África engatinha como área de discussão e pesquisa em nossas universidades. Por conta disso, há "uma assimetria entre o conhecimento das sociedades europeias, ameríndias e africanas" no país (MATTOS, 2003, p. 133). 
Não muito diferente é o tema da História e Cultura das Populações Indígenas, pois apesar de ter sido aprovada uma lei tornando obrigatório seu ensino nas escolas dos níveis fundamental e médio, em instituições públicas e privadas, temos que, necessariamente, verificar de que forma foi recepcionado nas diferentes escolas do país, ou mesmo nas instituições de ensino superior. Nesse caso, temos que prosseguir na pesquisa de como estão sendo estruturados coletivos sociais em prol desse projeto, que envolve a pesquisa e o ensino de História. Nesse aspecto, destacamos as palavras de Giovani José da Silva (2015, p. 53) de que o "Brasil é um país de rica diversidade, é pluricultural e multiétnico, embora existam aqueles que ainda têm dificuldades em reconhecer tal situação, quando não a desconhecem quase que completamente ou a escamoteiam propositalmente". Diante desses conflitos e tensões que se estendem para as instituições escolares, caberá verificar se pesquisadores que trabalham com essa temática, conforme Berger e Luckmann (1974), terão uma vara mais comprida para impor suas definições na realidade educacional do país no que diz respeito aos conteúdos de História e Cultura Afro-Brasileira e Indígena.

Em relação aos conflitos entre a proposta contida nos PCN e sua recepção em estados em municípios para os propósitos do nosso trabalho, enfatizamos o tema da cidadania. De acordo com esse documento federal, construir uma referência curricular nacional para o ensino fundamental tem o intuito que os alunos tenham acesso a conhecimentos indispensáveis para a construção da cidadania. Independentemente da área, a "apropriação dos conhecimentos socialmente elaborados é base para a construção da cidadania e da sua identidade" (BRASIL, 1998a, p.10). Mais de uma década depois, o governo federal voltou a reforçar a importância de se trabalhar esse conteúdo no sistema educacional do país. O documento produzido pelo INEP, em 2012, em sua Matriz de Referência de Ciências Humanas para o Enem, destaca que é fundamental "utilizar os conhecimentos históricos para compreender e valorizar os fundamentos da cidadania e da democracia, favorecendo uma atuação consciente do indivíduo na sociedade". (BRASIL, 2012).

Como destacamos, o MEC identificou a diversidade de propostas curriculares (61 propostas) elaboradas por secretarias de educação, secretarias 
municipais, tanto para o ensino fundamental como para o ensino médio. Dentre essas, nas Diretrizes Curriculares para o Ensino Básico no Estado do Paraná o paradigma de leitura, no que diz respeito, especificamente, ao tema da cidadania, foi no sentido de afirmar que os PCNs apresentavam a História de forma pragmática, como se ela tivesse a função de resolver problemas imediatos e próximos ao aluno. Com essa perspectiva de abordagem tinha aberto "espaço para uma visão presentista da História, porque não se ocupava em contextualizar os períodos históricos estudados" (PARANÁ, 2008, p. 43). Como podemos observar, o paradigma de leitura dos formuladores do Paraná foi no sentido de rebater o que havia sido formulado pelo governo federal no que se refere ao tema da cidadania, e de que na perspectiva pedagógica dos PCNs a "preocupação maior era de preparar o indivíduo para o mercado de trabalho" (PARANÁ, 2008, p. 43).

Diante disso, o termo cidadania aparece somente no início do documento das Diretrizes do Paraná, na Carta da Secretária de Educação e quando se faz a crítica da forma como o tema é abordado no documento do governo federal. Alguns conteúdos sobre direitos, como direito do aluno, direitos trabalhistas, direito à terra, direito nas sociedades contemporâneas, direitos humanos, não aparecem relacionados ao tema da cidadania. Direitos civis e políticos sequer são mencionados nas diretrizes do estado do Paraná.

Assinalamos que outros pesquisadores da área de ensino entenderam que o ensino de História poderia contribuir para abordar esse tema, haja vista que mostraria como a cidadania não é uma ideia abstrata ou natural, mas uma construção histórica, do mesmo modo que é cultural, pois foi produzida por homens e mulheres nas relações sociais concretas (GUIMARÃES, 2016). Quanto à visão presentista da História, podemos afirmar que a história do tempo presente já não é mais novidade, pois foi constituída uma metodologia da ciência da História a qual permite que o historiador, como qualquer outro, não isole os objetos de pesquisa apenas na fluidez da atualidade, mas inscreva a operação historiográfica na duração, na tessitura do tempo histórico. Rui Bebiano (2003, p. 226) enuncia que "este campo da história procede acima de tudo a uma arqueologia do presente, aproximando o conhecimento daquilo que se passa à nossa frente dos seus fundamentos mais ou menos profundos". 
Diante desses impasses, avaliamos que podem ocorrer problemas para a legitimação de universos simbólicos, pois definições distintas provocam no indivíduo a sensação de insegurança do que realmente considera ser o lugar certo das coisas quando desempenha seu papel enquanto agente educativo. Berger e Luckmann (1974, p. 144) ponderam que sempre haverá problema de transmissão do universo simbólico, já que nenhuma socialização é completamente bem-sucedida, alguns indivíduos podem habitar o universo transmitido de maneira mais definida do que outros. Estes autores nos alertam ainda que "para entender o estado do universo socialmente construído em qualquer momento, ou a variação dele com o tempo, é preciso entender a organização social que permite aos definidores fazerem sua definição" (BERGER; LUCKMANN, 1974, p. 157).

\section{Considerações finais}

Diante das novas propostas curriculares e experimentos pedagógicos da década de 1990, procuramos apresentar uma proposta de análise das instituições escolares, e do ensino de História, a partir do pressuposto teóricometodológico de que os textos educacionais não são redutíveis à intenção dos seus autores. Sendo assim, torna-se fundamental identificarmos os paradigmas de leituras entre os agentes educativos, seja nas secretarias de educação, equipe pedagógica nas escolas, seja entre professores na sala de aula.

Outro aspecto que consideramos essencial para avançarmos na compreensão desse tema é o contraste entre o desenho formal e as produções reais das instituições escolares no país. Podemos sublinhar que diante de um sistema educacional fragmentado, nos deparamos com espaços de significação distintos, que constituíram universos simbólicos diferenciados a partir da realidade social na qual estavam inseridos. Nesse sentido, lembramos que a criação de espaços de significação diferenciados pode provocar problemas de legitimação de novos universos simbólicos.

Se houve intenção de implantar uma política pública em torno dos ideais da democracia e da cidadania, temos que observar como esse tema foi 
recepcionado nos espaços educacionais e por professores em sala de aula. Mesmo porque, como pontuamos, as disciplinas não são meros espaços de vulgarização de saberes e o professor não é um mero respondente, mas um agente que elabora uma linha de ação de acordo com os elementos que verifica. Portanto, os textos educacionais ficaram sujeitos a modificações, e reformulações, em função dos agentes educativos agirem de acordo com as interações sociais estabelecidas com a sociedade.

\section{Referências}

ABUD, Kátia. Currículos de História e políticas públicas: os programas de História do Brasil na escola secundária. In: BITTENCOURT, Circe. O saber histórico na sala de aula. São Paulo: Contexto, 1997. p. 28-41.

AZANHA, José Mário Pires. Parâmetros Curriculares Nacionais e a autonomia da escola. In: VALLE, Bertha de Borjas Reis do et al. Políticas Públicas. Curitiba: IESD Brasil, 2009.

BEBIANO, Rui. Temas e problemas da História do presente. In: D 'ENCARNAÇÃO, José. A História tal qual se faz. Lisboa: Colibri, 2003. p. 225-236.

BERGER, Peter; LUCKMANN, Thomas. A construção social da realidade. Petrópolis: Vozes, 1974.

BITTENCOURT, Circe. Capitalismo e cidadania nas atuais propostas curriculares de História. In: BITTENCOURT, Circe. O saber histórico na sala de aula. São Paulo: Contexto, 1997. p. 11-27.

BLUMER, Herbert. A natureza do interacionismo simbólico. In: MORTENSEN, C. David. Teoria da comunicação: textos básicos. São Paulo: Editora Mosaico, 1980. p. $119-138$

BRASIL. Constituição (1988). Constituição da República Federativa do Brasil. Brasília, 1988.

BRASIL. Lei no 9.394, de 20 de dezembro de 1996. Lei de Diretrizes e Bases da Educação. Brasilia, 1996. Disponivel em: <http://www.planalto.gov.br/ccivil_03/ leis/l9394.htm>. Acesso em: 22 fev. 2017.

BRASIL. Ministério da Educação. Instituto Nacional de Estudos e Pesquisas Educacionais Anísio Teixeira. Matriz de Referência ENEM - Matriz de Referência de Ciências Humanas e suas Tecnologias. Brasília, 2012. Disponivel em: <http://download.inep.gov.br/educacao_basica/enem/downloads/2012/matriz_r eferencia_enem.pdf>. Acesso em: 22 fev. 2017. 
BRASIL. Ministério da Educação. Parâmetros Curriculares Nacionais: História. Brasília, 1998b.

BRASIL. Ministério da Educação. Parâmetros Curriculares Nacionais: terceiro e quarto ciclos: apresentação dos temas transversais. Brasília, 1998c.

BRASIL. Ministério da Educação. Parâmetros Curriculares Nacionais: terceiro e quarto ciclos do ensino fundamental: introdução aos parâmetros curriculares nacionais. Brasília, 1998a.

Brasil. Ministério da Educação. Secretaria de Educação Fundamental. Programa de desenvolvimento profissional continuado (Parâmetros em Ação). Brasília, 1999.

CARVALHO, José Murilo. Cidadania no Brasil: o longo caminho. Rio de Janeiro: Civilização Brasileira, 2005.

CHARTIER, Roger. Textos, impressão e leitura. In: HUNT, Lynn. A nova história cultural. São Paulo: Martins Fontes, 1992. p. 211-238.

DOUGLAS, Mary.Como pensam as instituições. Lisboa: Instituto Piaget, 2004.

DREYFUS, Françoise. La invención de la burocracia: servir ao Estado en Francia, Gran Bretaña y Estados Unidos (siglos XVIII-XX). Buenos Aires: Biblos, 2012.

GALIAN, Cláudia Valentina Assumpção. Os PCNs e a elaboração de propostas curriculares no Brasil. Cadernos de Pesquisa, São Paulo, v. 44, n. 153, p. 648669, jul./set. 2014.

GOODSON, Ivor F.As políticas de currículo e de escolarização. Petrópolis: Vozes, 2013.

GUIMARÃES, Selva (Org.). Ensino de História e cidadania. Campinas: Papirus, 2016.

GUIMARÃES, Selva; SILVA, Marcos. Ensinar História no século XXI: em busca do tempo entendido. Campinas: Papirus, 2012.

MATTOS, Hebe Maria. O ensino de História e a luta contra a discriminação racial no Brasil. In: ABREU, Martha; SOIHET, Rachel (Org.). Ensino de História: conceitos, temáticas e metodologia. Rio de Janeiro: Casa da Palavra, 2003. p. 127-138.

MEAD, Georg. Espíritu, persona y sociedad. Madrid: Paidós, 2010.

PARANÁ. Secretaria de Estado da Educação. Diretrizes Curriculares da Educação Básica - História. Curitiba, 2008.

PERRENOUD, Philippe. Escola e cidadania: o papel da escola na formação para a democracia. Porto Alegre: Artmed, 2005. 
SCHMIDTH, Maria Auxiliadora. A formação do professor de História e o cotidiano de sala de aula. In: BITTENCOURT, Circe. O saber histórico na sala de aula. São Paulo: Contexto, 1997.

SILVA, Giovani José da. Perspectivas do Ensino de História e diversidade Étnicocultural. In: ZAMBONI, Ernesta e outros (Org.). Memória, sensibilidades e saberes. Campinas: Editora Alínea, 2015.p. 52-63.

SILVA, Giselda Costa da. A História da África e da cultura Afro-brasileira: os saberes e fazeres dos professores. In: ZAMBONI, Ernesta e outros (Org.).

Memória, sensibilidades e saberes. Campinas: Editora Alínea, 2015.p. 193-208.

SILVA, Marcos Antonio da; FONSECA, Selva Guimarães. Ensino de História hoje: errâncias, conquistas e perdas. Revista Brasileira de História, São Paulo, v. 31, no 60, p. 13-33, 2010.

WEBER, Max.Economia e sociedade. São Paulo: Editora UNB, 1999. 